\title{
O PAPEL DOS HOSPITAIS UNIVERSITÁRIOS NO SUS: AVANÇOS E RETROCESSOS
}

\author{
Ivan Felizardo Contrera Toro ${ }^{1}$
}

\section{RESUMO}

Os hospitais universitários vem atravessando uma crise de décadas, no que se refere a financiamento, gestão, inserção no SUS e relacionamento com a academia. A necessidade de mudanças neste modelo culminou com uma discussão de um programa entre gestores federais, estaduais, municipais e diversos membros da área hospitalar no sentido de recertificação e contratualização dos hospitais universitários, o que representa um avanço na implantação da integralidade e equidade do atendimento público.

PALAVRAS-CHAVES: Hospital Universitário; Reforma Hospitalar; SUS; Atendimento Integral.

Os hospitais universitários de ensino (HUs), apresentam na sua grande maioria uma situação conflitante: ao mesmo tempo em que são responsáveis por grande parte do ensino das equipes de saúde e do dos tratamentos mais sofisticados do SUS, por outro lado atravessam, nas últimas décadas, dificuldades crescentes de preservação da sua missão.

Estas dificuldades estão centradas principalmente na sua relação com a academia, no atendimento despersonalizado, na inserção no SUS, na gestão interna e no financiamento.

Historicamente, principalmente antes de 1992, o modelo de HUs foi aquele onde o hospital era usado somente como um campo de treinamento técnico, principalmente das equipes médicas, sem vínculo nenhum com o sistema de saúde, com gestão não profissionalizada e submetida ao mérito acadêmico, significando que os docentes mais

\footnotetext{
${ }^{1}$ Chefe da Disciplina de Cirurgia Torácica do Departamento de Cirurgia da Faculdade de Ciências Médicas e Superintendente do Hospital das Clínicas da Universidade Estadual de Campinas.

\begin{tabular}{llllll}
\hline Serviço Social \& Saúde & Campinas & v. 4 & n. 4 & p. 1-156 & Maio 2005
\end{tabular}
}


graduados eram os mais influentes. Por isso, eram tratados, tanto pelo Ministério da Saúde (MS) como pelos gestores do SUS como hospitais não estratégicos na rede de atendimento.

A partir da implementação da constituição de 1988, com conseqüente normatização do SUS, que garantia não só o atendimento a todos os brasileiros, mas também as noções de integralidade e equidade do tratamento, começou a haver um movimento de colocar para os HUs o papel de referência de atendimento complexo.

Isto por um lado foi extremamente interessante para os usuários, pois no HUs estavam concentradas as maiorias do saber e do avanço tecnológico, porém por outro lado sobrecarregou a instituição que não estava preparada para receber um grande fluxo de pacientes, na maioria com procura espontânea e não necessariamente com indicação de tratamento em unidade especializada e onerosa como nos HUs. Essa desorganização do sistema, que persiste ainda nos dias de hoje, municiou os críticos do sistema com argumentos contra a integração no SUS, com a ameaça de descaracterização do papel do hospital de ensino.

Alguns hospitais universitários resistiram, mas o Hospital das Clínicas da UNICAMP teve um papel pioneiro em vislumbrar sua responsabilidade e foi um dos primeiros a assinar o contrato com o gestor federal.

Esta aposta mostrou correta: os anos subseqüentes foram pródigos em avanços na melhoria da produtividade, na expansão e principalmente na qualificação do ensino, da assistência e da pesquisa. Porém a relação conflituosa com a sociedade, o aumento de custos pela incorporação de tecnologia e falta de profissionalização novamente ameaçaram a sobrevida institucional.

A partir da desvalorização do real frente ao dólar no final da década de 90, esta situação de risco ficou potencializada, desviando a crise para o viés do financiamento. A solução seria somente aumentos de tabelas de procedimentos, fim dos tetos financeiros e físicos impostos pelos gestores, perdão das dívidas acumuladas, etc.

Esta situação foi sendo agravada até 2003, quando o MS, reconhecendo a necessidade de sair da mesmice, criou uma comissão composta por vários ministérios (Saúde, Educação, Planejamento e Ciência \& Tecnologia), representante dos hospitais de 
ensino (ABRAHUE, hospitais estaduais, federais e filantrópicos), ABEM, representantes de alunos, gestores (CONASS, CONASEM) e parlamentares.

Esta comissão estudou e discutiu toda a situação do HUs, principalmente a sua diversidade de problemas e após 18 meses começou a esboçar uma proposta de contratualização que consistia em não somente um aumento financeiro, mas em um contrato que estabelecia metas para, principalmente, quatro tópicos: gestão, inserção no SUS , humanização e qualidade.

Aliás, o aumento de receita decorrente desta nova contratualização começou a ser indutor de mudanças: este aumento e o antigo FIDEPS (incentivo para hospitais de ensino universitário) ficou dividido em duas partes: 90\% fixa e 10\% dependentes do comprimento de metas relacionadas aos tópicos acima. Pela primeira vez, os HUs receberiam mais dinheiro sem necessitar aumentar seu número de atendimento, mas sim de melhorar parâmetros de qualidade.

No caso do HC-UNICAMP, nossas metas principais foram diminuir filas, aumentar horários de visitas, ceder consultas de casos novos de especialidade para o gestor estadual, aumentar a disponibilidade de leitos de UTI, diminuir tempos de internação, reduzir as taxas de infecção hospitalar, diminuir o número de cesáreas (CAISM), realizar pesquisa de satisfação com os usuários, incluir funcionários, pacientes e alunos na comissão de acompanhamento do contrato.

No nosso ponto de vista, esta mudança municia a administração do hospital com instrumentos (as metas) que induzem todo o hospital a caminhar na direção de um aumento de produtividade, de negociação com a academia e de participação de toda a comunidade.

Este passo é um grande avanço, mas resolve somente parte de um tripé de sustentação dos HUs: falta um projeto consistente que resolva o passado (Dívidas acumuladas) e o futuro (investimentos).

A questão das dívidas dos hospitais, acumuladas nos últimos anos de arrocho pode comprometer toda a melhoria do plano de contratualização. A maioria dos hospitais alcança o equilíbrio entre despesa e receita com este novo método de financiamento, mas continua sem capacidade de poupança para pagamento de atrasados, que só nos Hospitais de Ensino federais em 2004 alcançava perto de R\$ 400.000.000,00. Os hospitais \begin{tabular}{llllll}
\hline Serviço Social \& Saúde & Campinas & v. 4 & n. 4 & p. 1-156 & Maio 2005
\end{tabular} 
filantrópicos e estaduais devem ter dívidas equivalentes e urge a necessidade disto ser entendido como um passivo em que o gestor tem responsabilidade pelo desfinaciamento do passado. Esta questão talvez seja a mais complexas porque envolve além do fato acima (desfinanciamento) questões como papel das fundações privadas, erros na gestão, omissão das universidades em reposição de pessoal nos hospitais, desvinculação entre investimentos passados e aumentos de tetos, etc. Mas deve existir a coragem de todas as partes envolvidas na discussão e encaminhamento de solução.

Finalmente, para completar o tripé de sustentação da viabilidade dos HUs, é necessário uma política clara de investimentos, que contemple a situação de sucateamento das instalações físicas e de equipamentos que grande parte dos hospitais se encontram. Fácil de entender que com dívidas acumulando e dificuldades no dia-a-dia dos hospitais, a manutenção, a prevenção, a atualização tecnológica e produtividade tenham ficado em segundo plano.

Nestes últimos anos, os investimentos aconteceram com programas do MS (REFORSUS, QUALISUS, etc.), dos governos estaduais e pouco das universidades e mantenedoras. Mesmo estes esforços não acrescentaram muitos avanços, pois em alguns casos estavam descolados de programas de manutenção (que são extremamente onerosos) e de custeio financeiro (ausência de teto específico e acréscimo de despesa decorrente de novas tecnologias). É necessário inovar: a recuperação de hospitais como um todo, com financiamentos de reformas e equipamentos, juntamente com acréscimos de receitas que possibilitem cumprir os compromissos decorrentes deste financiamento e não menos importante, um plano nacional de qualificação dos diversos níveis de trabalhadores e gerencias em saúde.

Finalmente resta comentar rapidamente duas possibilidades usadas pela maioria dos hospitais públicos universitários no Brasil: o atendimento a não SUS (convênios e particulares) e parcerias com iniciativa privada.

Quanto ao atendimento de convênio e particulares, a história mostra que na maioria dos hospitais pode ser uma pequena fonte de rendimento, porém em hipótese alguma deve competir com o paciente SUS e nem deve ter atendimento preferencial ou com acomodações especiais, visto que todo investimento inicial físico e humano é publico. No \begin{tabular}{llllll}
\hline Serviço Social \& Saúde & Campinas & v. 4 & n. 4 & p. 1-156 & Maio 2005
\end{tabular} 
nosso ponto de vista o controle da administração para estes aspectos é difícil e não pode ser negligenciado.

Em relação às parcerias com a iniciativa privada, estas podem e devem investir nos HUs, principalmente em reformas, equipamentos e treinamento, porém sem ser privilegiadas com atendimento especial no encaminhamento de pacientes ou vantagens licitatórias. As vantagens devem ser limitadas a melhoria da imagem parceira e eventual abatimento de impostos que a lei prevê.

Apesar de todas dificuldades, os Hospitais Universitários tem cumprido um papel na saúde pública indispensável na evolução do SUS e deve ser olhado como um elo fundamental do avanço da democracia sanitária no Brasil.

\section{ABSTRACT}

The university hospitals have gone through decades of crises concerning financing, administration, SUS integration and academy relationship. The need to change this model demanded debates of a program involving federal, state and county administration as well as debate among members of the hospital staff area. This discussion emphasized the need of re-certification and contractualization of university hospitals and represents an improvement in public health care regarding integrality and equity.

KEY-WORDS: University Hospital, Hospital Reform, SUS, Integral Care.

\section{BIBLIOGRAFIA CONSULTADA}

BITTAR, Olímpio J. Nogueira V. Indicadores de Qualidade e Quantidade em Saúde. Parte II. RAS - Vol. 6, nº 22 - jan./mar, 2004.

BRASIL.Ministério da Saúde. Secretaria Nacional de Assistência à Saúde. ABC do SUS: Doutrinas e Princípios. Brasília/DF, 1990.

BRASIL.Ministério da Saúde. Ministério da Educação e Cultura. Instrumento de Avaliação e Monitoramento do HUES. www.saude.gov.br/sas/

CECÍLIO, Luiz Carlos de Oliveira. As Necessidades de Saúde como Conceito Estruturante na Luta pela Integralidade e Eqüidade na Atenção. Campinas: DMPS/FCM/UNICAMP. Nov. 2001.

\begin{tabular}{llllll}
\hline Serviço Social \& Saúde & Campinas & v. 4 & n. 4 & p. 1-156 & Maio 2005
\end{tabular} 
CECÍLIO, Luiz Carlos de Oliveira e MERHY, Emerson Elias. A Integralidade do Cuidado como Eixo da Gestão Hospitalar. Campinas, DMPS/FCM/Unicamp

MERHY, E. E. Perspectivas Atuais do SUS e o Agir Tecnológico do Trabalhador como um Ato Ético-Político. Serviço Social \& Saúde, n 3, p. 1-11, 2004. 